\title{
Mitigation as an Effort to Reduce Disease Numbers and Doctor Death Due to Covid-19
}

\author{
Rospita Adelina Siregar \\ Faculty of Law, Universitas Kristen Indonesia, Jakarta Timur \\ \{rospita.siregar@uki.ac.id\}
}

\begin{abstract}
The death of doctors due to Covid-19 in various regions in Indonesia during a period of time that continues to increase with various types of medical professions such as general practitioners, doctors in specialist education and specialist doctors. Through a medical study of the cause of death of doctors using primary data from the PB IDI Team, the data that was studied qualitatively resulted from the fact that 303 doctors who died due to Covid 19 were mostly general practitioners $(55,8 \%)$ and specialist doctors $(44.2 \%)$, male doctors $(85 \%)$ and female doctors $(15 \%)$, the highest age distribution was over 45 years $(81.2 \%)$. The main factors overcoming physical and mental. Statement on the application of Law No. 24 of 2007 concerning Disaster Management emphasizes that mitigation efforts are carried out through efforts to reduce disasters, both through physical development and awareness and increased capacity to face disasters, aimed at medical personnel as the frontline.
\end{abstract}

Keywords: Doctor's Death; Mitigation; Covid-19

\section{Introduction}

The performance of a doctor who works professionally during this pandemic demands more than what is described in law number 29 of 2004 concerning Medical Practice in article 44 which only explains that in carrying out medical practice it is mandatory to follow medical service standards and in paragraph 2 it stated that service standards as referred to in paragraph (1) shall be distinguished according to the types and strata of health service facilities.

The level of health service facilities varies in all regions, this is greatly influenced by the natural conditions and the archipelago, that the total area of Indonesia reaches 5,180,053 km2, consisting of a land area of $1,922,570 \mathrm{~km} 2$ and a sea of $3,257,483 \mathrm{~km} 2$ with the number of islands reaching 16,056 in 2018. Data taken data from the Ministry of Home Affairs (Kemendagri) states that the total population of Indonesia as of December 2020 has reached 271,349,889 people, in it 107.007 general practitioners who work throughout Indonesia. Doctors work in health care facilities from level 1 to level of referral or referral hospital.

Law Number 44 of 2009 concerning Hospitals, it is stated that the definition of a hospital is a health service institution for the community with its characteristics which are influenced by the development of health science, technological advances, and the socio-economic life of the community which must continue to be able to improve quality services and affordable by the community to realize the highest health standard. 
Besides, in Law Number 36 of 2009 concerning health, it is emphasized that everyone has the same rights in obtaining safe, quality, and affordable health services. Health services are determined by management which has characteristics, the existence of goals to be achieved, the existence of resources, efforts to mobilize resources, the presence of people who move the resources (managers), and the existence of a planning-organizing-moving-implementationdirection-and-control process. There are three important reasons an organization needs to implement management, namely to achieve organizational goals, maintain a balance of objectives within the organization, and achieve organizational goals efficiently and effectively.

In Permenkes 30 of 2019 concerning hospital classification and licensing, Article 6 letter a explains that a hospital is a health service institution that provides complete individual health services that provide inpatient, outpatient, and emergency services. Providing health services in all fields and types of diseases. Health services provided by public hospitals as referred to in paragraph (1) at least consist of: a. medical services; b. nursing and midwifery services; c. medical support services; and D. non-medical support services.

There are three types of classification of health services, throughout the world, divided health service strata as follows:

a. Primary health care. It is a basic health service, general outpatient (ambulatory/outpatient services).

b. Secondary health services. Further health services that are inpatient (in patient services).

c. Tertiary health services. Health services that are more complex in nature and are provided by subspecialists.

Hospital classification is divided according to the Law of the Republic of Indonesia number 44 of 2009 concerning Hospitals, into a classification of health services in general hospitals and special hospitals.

a. Classification of general hospitals as denoted in paragraph (1) consists of:

1. General Hospital Class A;

2. General Hospital Class B;

3. General Hospital Class C;

4. General Hospital Class D

b. The classification of the Specialty Hospital as referred to in paragraph (1) consists of:

1. Specialty Hospital Class A;

2. Special Hospital Class B;

3. Specialty hospital Class C.

\section{Research Problem}

The death of doctors in carrying out the task of dealing with Covid-19, assuming there is a gap between Human Resources who are required to work in a standardized manner and the diversity of types and levels of service facilities in hospitals. The number of doctor deaths continues to increase from the previous data on February 10, 2021, of 317 people.

\section{Result and Discussion}

As the vanguard in efforts to treat Covid-19 patients, medical personnel, including doctors, are the most vulnerable group because they interact directly with positive and suspected 
Covid-19 patients. Doctors are bound by their obligation to help patients recover. Death of health workers due to Covid-19 has become an important problem, because of the strategic position of health workers as well as the accompanying domino effect, but various policies that exist/are proposed are still limited to efforts to reduce transmission to health workers, not yet aimed at reducing the death of infected health workers Covid19. It is recommended that the central government and related stakeholders: 1) Make the issue of reducing the morbidity and mortality rate of health workers caused by Covid-19 a national priority, 2) Develop and run the Covid-19 Morbidity and Mortality Reduction Program (C19-MMRP) for health workers.

Since March 2020 or when the first case of Covid-19 appeared in Indonesia until January 2021, there was 647 medical and health personnel who died as a result of being infected with the corona 19 virus. The number consisted of 289 doctors (16 professors) and 27 dentists (3 teachers). large), 221 nurses, 84 midwives, 11 pharmacists, and 15 medical laboratory personnel. Based on the available data, it was found that the death of doctors mainly occurred in the group of doctors who were over 50 years of age, were general practitioners, had comorbidity, and were still productive to work.

Analysis of the death cases of health workers mainly tries to answer two things: the mechanism of health workers contracting Covid-19, and the quality of management of health workers who have contracted Covid-19. Various assumptions that are often used to explain why health workers are infected with Covid-19 is that health workers are not responsive when serving patients who are carriers of the Covid-19 virus, in working health workers do not use adequate/standard Personal Protective Equipment / PPE, a sense of physical fatigue issues, and physical disorder.

Other factors, namely from health service facilities (Faskes), to related social activities of health workers outside the health facilities. Assumptions are made based on the data set of the doctor's death investigation team conducted by the Indonesian Doctors Association (IDI). The quality of management of health workers who have contracted Covid-19 is more difficult to answer, difficulties in obtaining a history of past and present illnesses, although it is believed that the doctors who treat them have tried to provide the best service to their peers, the systematic death audit activity temporarily ensures that the death of the worker health that is infected with Covid-19 is unavoidable (death that cannot be prevented according to medical science), or there are sub-standard services in dealing with the clinical manifestations of Covid-19, so that death is classified as avoidable death, so there needs to be follow-up in the form of improving the quality of management.

Current government policies in Covid-19 are mainly focused on efforts to prevent the spread and transmission of the virus. Another policy focus is on recording incidents and deaths for epidemiological monitoring, even though it is publicly accessible, it does not contain sufficient clinical data that can be used as a mortality analysis (death audit) including deaths among health workers.

Efforts to tackle national covid19 usually include the formation of an incident management team (IMT). The person in charge (focal point) who seriously takes care of primary health services must be a member of the IMT acting as a liaison with the essential service program. It is in an epidemic stage where the caseload of Covid-19 can be managed without compromising routine services. In dealing with the Covid-19 case, doctors are currently required to work according to the standards set by the Ministry of Health with input from several expertise associations such as pulmonary, cardiovascular, internal medicine, anesthetist, and pediatricians. Then the Guidelines for the Management of COVID-19 5OP Edition III, 2020 were introduced. 
Quoting a statement by IDI management who said that Covid-19 vaccination was the most ethical way to achieve herd immunity. The most ethical way is that used by the government by giving vaccinations, but it is reminded that vaccination is not the only way to stop the transmission of Covid-19, people are still required to be disciplined in applying health protocols. Vaccination is the secondary prevention, which is to prevent people from getting sick and if they are not so severe. The positivity rate still increased at the end of February by $26.19 \%$. It means that there will be an impact on increasing cases of death from Covid-19. Currently, the implementation of vaccination is being implemented, which has an impact on the decline in the use of beds or bed occupancy rate (BOR) at the Covid-19 patient referral hospital.

Inside Law Number 36 of 2009 concerning health, it is emphasized that everyone has the same rights in obtaining safe, quality, and affordable health services. One of the goals of improving the quality of health services is patient satisfaction. Satisfaction is a feeling of pleasure or disappointment in someone who appears after comparing the impression of performance or results and expectations. Health services are determined by management which has characteristics, the existence of goals to be achieved, the presence of resources, efforts to mobilize resources, the presence of people who move resources (managers), and the existence of planning, organizing, mobilizing, implementing, directing, and controlling processes. There are three important reasons an organization needs to implement management, namely to achieve organizational goals, maintain a balance of objectives within the organization, and achieve organizational goals efficiently and effectively.

Inside Law Number 44 of 2009 concerning Hospitals, it is stated that the definition of a hospital is a health service institution for the community with its characteristics which are influenced by the development of health science, technological advances, and the socioeconomic life of the community which must continue to be able to improve quality services and affordable by the community to realize the highest degree of health.

\section{Conclusion and Suggestion}

\subsection{Conclusion}

The impact of mortality for health workers is so large, even based on the comparison of statistical testing and population, the death of medical and health personnel in Indonesia is in the top three worldwide, causing a domino effect on the health system at the regional and national levels. With the high mortality rate for health workers due to Covid-19, the workload for health workers who are left will automatically increase, not only because of the reduced number of health workers but because the increased physical stress at work also affects the psychological burden. The existence of an increased workload will decrease the capacity of health services, especially in areas with shortages and scarcity of health workers. The next effect is increased community morbidity and mortality, not only because of Covid-19 but also due to other acute or chronic diseases.

\subsection{Suggestions}

a. As a form of mitigation for the death of doctors, the issue of reducing the morbidity and mortality rates for health workers due to Covid-19 is one of the national priorities. 
b. Assess whether after the implementation of the Covid-19 Morbidity and Mortality Reduction Program (C19-MMRP) vaccination for health workers has changed nationally.

\section{References}

[1] Hanevi Djasri, Consultant and Researcher at the Center for Health Policy and Management. Involved in Death Audit activities since 2003. FK KKMK UGM, Yogyakarta.

[2] PAPDI. Management Guidelines for COVID-19 5OP, Edition III, 2020.

[3] Rospita Adelina Siregar et al, 2020, Health Service Policy \& Management, Widina Publisher, Bandung, p. 232

[4] Law of the Republic of Indonesia number 29 of 2004 concerning Medical Practice

[5] Law of the Republic of Indonesia number 44 of 2009 concerning Hospitals

[6] Law of the Republic of Indonesia number 36 of 2009 concerning Health

[7] Minister of Health Regulation 30 of 2019 concerning Hospital Classification and Licensing

[8] BPPSDMK 2021 data (http://bppsdmk.kemkes.go.id/info_sdmk/info/index?rumpun=1)

[9] The Head of the Indonesian Doctors Association (PB IDI) Executive Board Mitigation

[10] Team Adib Khumaidi said on Kompas.com the title "A year of Covid-19, IDI Highlights Doctor Death, Incentives and Vaccinations", Retrieved from https://nasional.kompas.com / read / 2021/03/02/11172871 / a year-covid-19-idihighlight-mortality-doctors-incentives-to-vaccination? page $=$ all

[11] Ministry of Home Affairs, Population data as of December 2020

[12] Maintaining-essential-health-services --- ind.pdf

[13] Kompas.com with the title "IDI: The Death of Indonesian Medical Workers in the Top 3 in the World". Article. Retrieved from https://nasional.kompas.com/read/2021/01/28/15003431/idi-kematian-tenaga-medisindonesia -3-big-in-the-world 